\title{
APROVEITAMENTO DE RESÍDUOS DE PAPEL PARA PRODUÇÃO DE CARVÃO ECOLÓGICO NA CIDADE DE NAMPULA ${ }^{1}$
}

\author{
UTILIZATION OF PAPER RESIDUES FOR PRODUCTION OF \\ ECOLOGICAL CHARCOAL IN NAMPULA
}

Felizardo Filomeno Abdala ${ }^{2}$

\begin{abstract}
RESUMO
O presente trabalho avalia o aproveitamento de resíduos de papel para a produção de carvão ecológico, vulgo briquete ecológico. A avaliação do potencial de aproveitamento dos resíduos de papel pode ser uma alternativa para gerar energia, diminuir o espaço ocupado por ess es resíduos nos aterros sanitários e, dessa forma, aumentar a vida útil dos mesmos e melhorar a limpeza dos espaços públicos. A produção de carvão ecológico usando esses resíduos irá permitir a preservação das florestas nativas ou plantadas como espécies exóticas e o incremento da cadeia produtiva da classe social menos favorecida para o auto sustento, além, da possibilidade de reaproveitamento dess es resíduos pelas entidades geradoras. Neste estudo, foi viabilizada a produção desse carvão através da avaliação custo-benefício comparando o tempo útil de emis são de calor térmico entre o carvão ecológico produzido a base de papel com o carvão vegetal produzido a base de lenha, sendo que o tempo médio útil de emissão de calor térmico para uma quantidade de 600 gramas de carvão em comparação com o carvão vegetal foi de 28 minutos e 42 minutos, respectivamente, gerando uma quantidade de cinza de 82.75 gramas contra 72 gramas de carvão vegetal. Os fatores como impacto visual, utilização de papel e volume de negócio foram os maiores indicadores para escolha das áreas amostrais pela disposição de resíduos. Foram produzidos durante os ensaios experimentais cerca de 10 sacos de $60 \mathrm{Kg}$ de carvão ecológico a um custo de $35 \mathrm{mt} / \mathrm{saco}$ de $60 \mathrm{~kg}$, valor muito abaixo do que o preço atual (250-270 mt) do carvão vegetal no mercado local. Participaram do evento experimental e da divulgação do processo 40 pessoas sendo 19 estudantes, 3 professores e 18 membros da comunidade.
\end{abstract}

Palavras-chaves: resíduo; aproveitamento; energia.

\begin{abstract}
This paper evaluates the use of paper residues for the production of ecological charcoal, called ecological briquette. Assessing the potential for using paper residues can be an alternative to generate energy, reduce the space occupied by this waste in landfills and thus increase their useful life and improve the cleanliness of public areas. The production of ecological charcoal using these residues will allow the preservation of native or planted forests as exotic species and the increase of the productive chain of the less favored social class for self-sustenance, besides the possibility of reuse of these residues by the generating entities. In this study, the production of this charcoal wasmade possible through the cost-benefit evaluation comparing the useful time of thermal heat emission between the paper-based ecologicalcharcoal and the wood-based charcoal. Besides, was used the average helpful time of thermal heat emission for an amount of 600 grams of charcoal compared to charcoal was 28 minutes and 42 minutes, respectively, generating an ash amount of 82.75 grams versus 72 grams of charcoal. Factors such as visual impact, paper use and turnover were the most significant indicators for choosing sample areas for waste
\end{abstract}

\footnotetext{
1 Texto escrito em português de Moçambique.

2 Engenheiro químico com mais de 10 anos de experiência na área de ensino e 6 anos como ambietaliata em processos de mineração e transporte de minério. E-mail: felizardo.abdala@gmail.com
} 
disposal. About $1060 \mathrm{~kg}$ bags of eco-charcoal were produced during the experimental trials at the cost of $35 \mathrm{mt} /$ $60 \mathrm{~kg}$ bag, much lower than the current price (250-270 mt) of charcoal on the local market. Forty people participated in the experimental event and the dissemination of the process, nineteen students, three teachers and eighteen community members.

Keywords: waste; utilization; energy.

\section{INTRODUÇÃO}

O modo de vida atual em Moçambique traz consigo uma elevada produção de resíduos, cuja eliminação constitui um grande problema de caráter ambiental. No entanto, com o aumento da consciência ambiental da população moçambicana e do consentimento das responsabilidades dos conselhos municipais, um número crescente de pessoas e administrações municipais estão se esforçando para encontrar as melhores soluções para os problemas dos resíduos sólidos urbanos (RSU).

Esses problemas são realmente novos quando comparados com décadas atrás e infelizmente não se resolvem de forma isolada. As situações são bem diferentes em cada município, porém, pode-se garantir que diante dos recursos humanos e materiais atualmente existentes e disponíveis em cada município, as dificuldades ainda são grandes, cabendo aos munícipes junto com o município procurarem soluções adequadas para gerir os resíduos sólidos urbanos.

\section{DISCUSSÃO TEÓRICA}

Segundo Grippi (2001), entende-se por gerenciar os resíduos sólidos na concepção da palavra, fazer acompanhamento, desde sua geração, seleção e disposição, a qual deve ter um destino ambiental e sanitário adequados, a fim de não contaminar o solo, o ar, as águas superficiais e subterrâneas e evitar a proliferação de vetores que podem causar doenças ao homem.

A crescente preocupação com a quantidade de resíduos sólidos produzidos e o aumento do custo da matéria-prima, aliados ao desenvolvimento de tecnologia, viabilizam o aproveitamento e reciclagem cada vez mais dos resíduos, promovendo economia de recursos 
naturais, diminuição da poluição ambiental, geração de empregos diretos e indiretos e redução do volume de material a ser disposto.

A reciclagem tem papel fundamental dentro do conceito de desenvolvimento sustentável, cabendo a cada pessoa fazer sua parte e cobrar eficiência do setor público, a quem cabe gerir os resíduos sólidos urbanos com eficiência e responsabilidade.

Em 2012, a publicação da estratégia de gestão integrada de resíduos sólidos urbanos em Moçambique foi um grande passo para a realização de um verdadeiro compromisso com o desenvolvimento sustentável e pode ajudar na gestão dos resíduos sólidos urbanos nas cidades, principalmente, no que diz respeito ao aumento da reutilização e reciclagem ambientalmente saudáveis dos resíduos.

\begin{abstract}
A estratégia de gestão integrada de resíduos sólidos urbanos em Moçambique tem por objetivo fornecer bas es para uma gestão integrada de resíduos sólidos, tendo em conta uma abordagem sistemática focalizando as componentes de minimização da produção, acondicionamento, recolha, transporte, tratamento e deposição final com vista a proteger a saúde pública, o ambiente e por conseguinte contribuir para combater a pobreza, providenciando diretrizes que permitam a criação de condições necessárias de prevenção da proliferação de resíduos sólidos nas cidades e vilas, definindo o papel de cada interveniente, incluindo o estado, os munícipes e os órgãos municipais, na gestão de resíduos sólidos urbanos (MICOA, 2012, p.3).

Segundo a lei Moçambicana do Ambiente $n^{\circ}$ 20/97 de 1 de outubro, capitulo I, Artigo I, ambiente é o meio em que o Homem e outros seres vivem e interagem entre si e com o próprio meio e inclui: o ar a luz a terra e a água; os ecossistemas e biodiversidade e as relações ecológica; toda matéria orgânica e inorgânica; todas as condições socioculturais e económicas que afetam a vida das comunidades (MOÇAMBIQUE, 1997).
\end{abstract}

No entanto, estimativas oficiais apontam para uma variação na produção anual de resíduos sólidos nos principais centros urbanos do país. A tabela 1 mostra uma produção anual de duzentas mil toneladas, o que corresponde a uma produção média de 548 ton/dia.

Estes dados tendem, no geral, a aumentar nos últimos anos. A título de exemplo, o inquérito feito aos serviços de salubridade do município da cidade de Nampula aponta para uma produção estimada em 300 mil toneladas de resíduos no ano de 2019, o que corresponde a uma produção média de 822 ton/dia e uma captação de $1.1 \mathrm{~kg} /$ habitante por dia. A tabela a seguir indica a produção dos resíduos sólidos em alguns centros urbanos do País. 
Tabela 1: produção de resíduos sólidos em Moçambique (2009)

\begin{tabular}{|l|c|}
\hline \multicolumn{1}{|c|}{ CENTROS URBANOS } & PRODUÇÃO (ton/ano) \\
\hline Maputo & 1.135 .000 \\
\hline Matola & 110.000 \\
\hline Xai-Xai & 17.163 \\
\hline Inhambane & 52.370 \\
\hline Vilankulo & 3.650 \\
\hline Beira & 162.060 \\
\hline Mocuba & 750 \\
\hline Quelimane & 4.500 \\
\hline Nampula & 200.000 \\
\hline Inha de Moçambique & 7.200 \\
\hline Nacala & 33.127 \\
\hline Pemba & 6.300 \\
\hline Mocimba da Praia & 2.160 \\
\hline Montepuez & 6.500 \\
\hline Total & 1.732 .450 \\
\hline Font Ministerio & \\
\hline
\end{tabular}

Fonte: Ministério de Coordenação da Ação Ambiental - MICOA (2009)

Porém, dados mais atualizados da evolução de geração de resíduos sólidos urbanos no município de Nampula no período 2015 a 2018 podem ser visualizados na tabela 2.

Tabela 1 : produção de resíduos sólidos no município de Nampula, ano 2015-2018

\begin{tabular}{|c|c|c|c|}
\hline \multirow{2}{*}{ Anos } & \multicolumn{2}{|c|}{$\begin{array}{c}\text { Quantidade de RSU } \\
\text { (t/ano) }\end{array}$} & $\begin{array}{c}\text { Percentagem } \\
\text { de Execucção }\end{array}$ \\
\cline { 2 - 3 } & Planificado & Realizado & \\
\hline 2015 & 250 & 188.637 & $75,45 \%$ \\
\hline 2016 & 250 & 193.590 & $74,40 \%$ \\
\hline 2017 & 300 & 163.335 & $54,44 \%$ \\
\hline 2018 & 300 & 170.994 & $57,00 \%$ \\
\hline
\end{tabular}

Fonte: Conselho Municipal da Cidade de Nampula (2019) 
A recolha de resíduos sólidos pelo serviço municipal não tem sido abrangente. Ao nível da cidade de Nampula o percentual de recolha varia de 55\% a $75 \%$ do total de resíduos sólidos, cobrindo basicamente a zona de cimento e parte suburbana, não incluindo a periurbana. Esses resíduos são recolhidos em contentores de $1 \mathrm{~m}^{3}, 3 \mathrm{~m}^{3}$ e $6 \mathrm{~m}^{3}$, dependendo da área, número de beneficiários e do meio de transporte.

Em Nampula, registrou-se redução de produção de carvão vegetal e corte de lenha, sendo que a taxa de variação média entre os anos de 2015 e 2018 foi de $11 \%$ para o caso de produção de carvão vegetal, enquanto que para o caso de corte de lenha é 14 \% além da redução massiva das áreas florestais que ronda nos $41 \%$, segundo revelam os dados dos Serviços Provinciais de Floresta e Fauna Bravia (SPFFB) apresentados na tabela 3.

Tabela 2: Produção de carvão vegetal em Nampula, ano 2015-2018

\begin{tabular}{|c|c|c|c|c|c|c|c|}
\hline \multirow{2}{*}{ Iten } & \multirow{2}{*}{ Medida } & \multicolumn{4}{|c|}{ Período } & \multirow{2}{*}{ Total } & \multirow{2}{*}{ TVM(\%) } \\
\hline & & 2015 & 2016 & 2017 & 2018 & & \\
\hline Carvão & $(\mathrm{st})$ & 67909 & 52258 & 55293 & 46372 & 232100 & $-11,12$ \\
\hline Lenha & $(\mathrm{st})$ & 3333 & 2629 & 5026 & 3994 & 16641 & 13,84 \\
\hline Área Florestal & $\mathrm{Ha}$ & 1.147 .6 & 920.6 & 114.3 & 96.53 & 2439.58 & -40.97 \\
\hline
\end{tabular}

Fonte: SPFFB (2019)

As experiências da vida e do cotidiano ao nível mundial demostram que a gestão de resíduos exige uma rigorosa pesquisa. O primeiro passo é a sistematização de experiências de recuperação através da coleta seletiva na fonte de geração, reutilização e reciclagem de resíduos de distintos materiais (restos alimentícios, plásticos, papeis, vidros, metais etc.); o segundo passo é o estudo de possibilidades de adaptação de experiências eficazes às realidades locais; e o terceiro é a pesquisa e o desenvolvimento de experiências locais que permitam gerar novos processos produtivos a partir de resíduos.

A título de exemplo, em 2015 o saco de $60 \mathrm{~kg}$ de carvão vegetal custava 130 meticais $^{3}$ e em 2018 passou para 200 meticais contra os atuais 250-270mt, sendo imprescindível a criação de alternativas de fornecimento de energia para fins domésticos de modo a fazer face à procura

\footnotetext{
${ }^{3}$ Metical de Moçambique é a moeda oficial de Moçambique.
} 
e ao preço, possibilitando assim a redução do abate de árvores para a produção do carvão vegetal como garantia da sustentabilidade do recurso natural, além da valorização desse resíduo. A fotografia 1 evidencia os preços atuais praticados no mercado de venda de carvão vegetal em alguns bairros da cidade de Nampula.

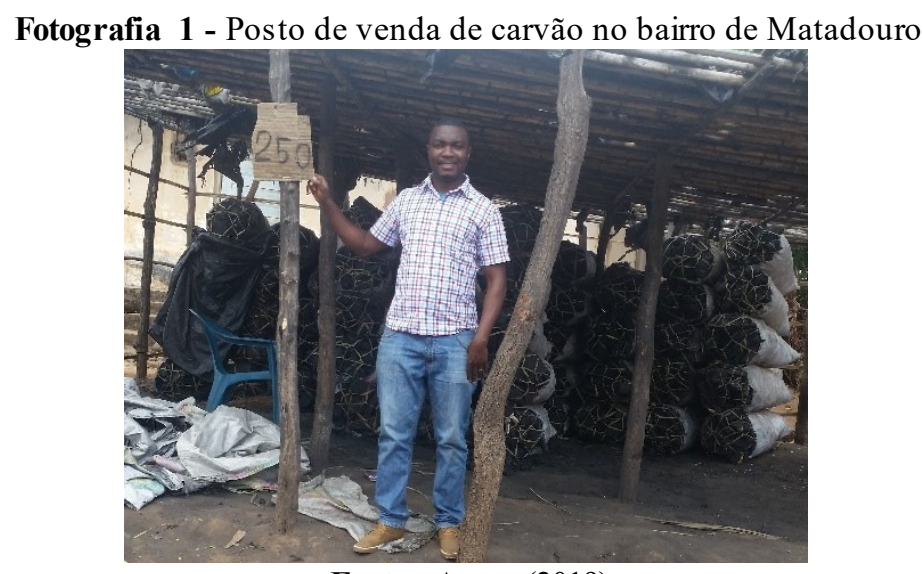

Fonte: Autor (2019)

É pouco comum ouvir sobre o aproveitamento de resíduos de papel em Moçambique, quer nas empresas ou na comunidade em geral, mas o grito sobre a preocupação com resíduos sólidos urbanos é coletivo, tornando-o um problema que necessita de criação de metodologias que garantam o tratamento dos mesmos em todos os setores e organizações.

O diagnóstico efetuado mostra (fotografia 2) a presença de resíduos de papel em todos os espaços da cidade, falta de separação e disposição de RSU em locais não adequados.

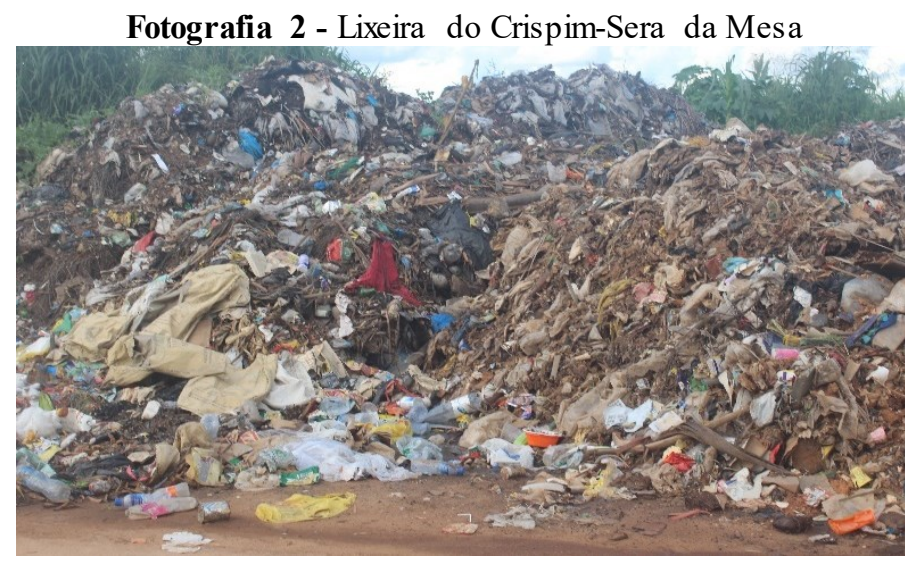

Fonte: Autor (2019) 


\title{
2.1. Caracterização e Delimitação da Área de Estudo
}

Nampula é uma província situada na região norte de Moçambique. A sua capital é a cidade de Nampula, localizada a cerca de $2.150 \mathrm{~km}$ a norte da cidade de Maputo, a capital do país possui uma área de $81.606 \mathrm{~km}^{2}$ e uma população de 6.102 .867 habitantes, conforme dados do último Censo (INE, 2017)

\begin{abstract}
Situa-se aproximadamente, no centro do espaço geográfico do distrito que leva o mesmo nome (Distrito de Nampula) um pouco deslocado para NE, e ocupa uma área de $404 \mathrm{~km}^{2}$. De Este para Oeste tem uma extensão de $24 \mathrm{~km}$ entre os meridianos de $39^{\circ} 23^{\prime} 28^{\prime \prime}$ e $39^{\circ} 10^{\prime} 00^{\prime \prime}$ Este. No Sentido Norte-Sul estende-se por $20,25 \mathrm{~km}$, desde a barragem do rio Monapo a uma altitude de $15^{\circ} 01^{\prime} 35^{\prime \prime}$ até ao riacho Muepelume,

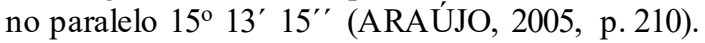

O limite da artéria da cidade de Nampula escolhido para o estudo compreende uma faixa circular que abrange as seguintes instituições: i) Norte-Barragem de Monapo; ii) Sul-Bairro Canloca; iii) Este-fábrica de processamento de castanha de caju; iv) Oeste cervejas de Moçambique; v) Sudoeste-Licheira Municipal Crispim; vi) Noreste-Hospital Geral de Marere, segundo mostra a figura 1 :

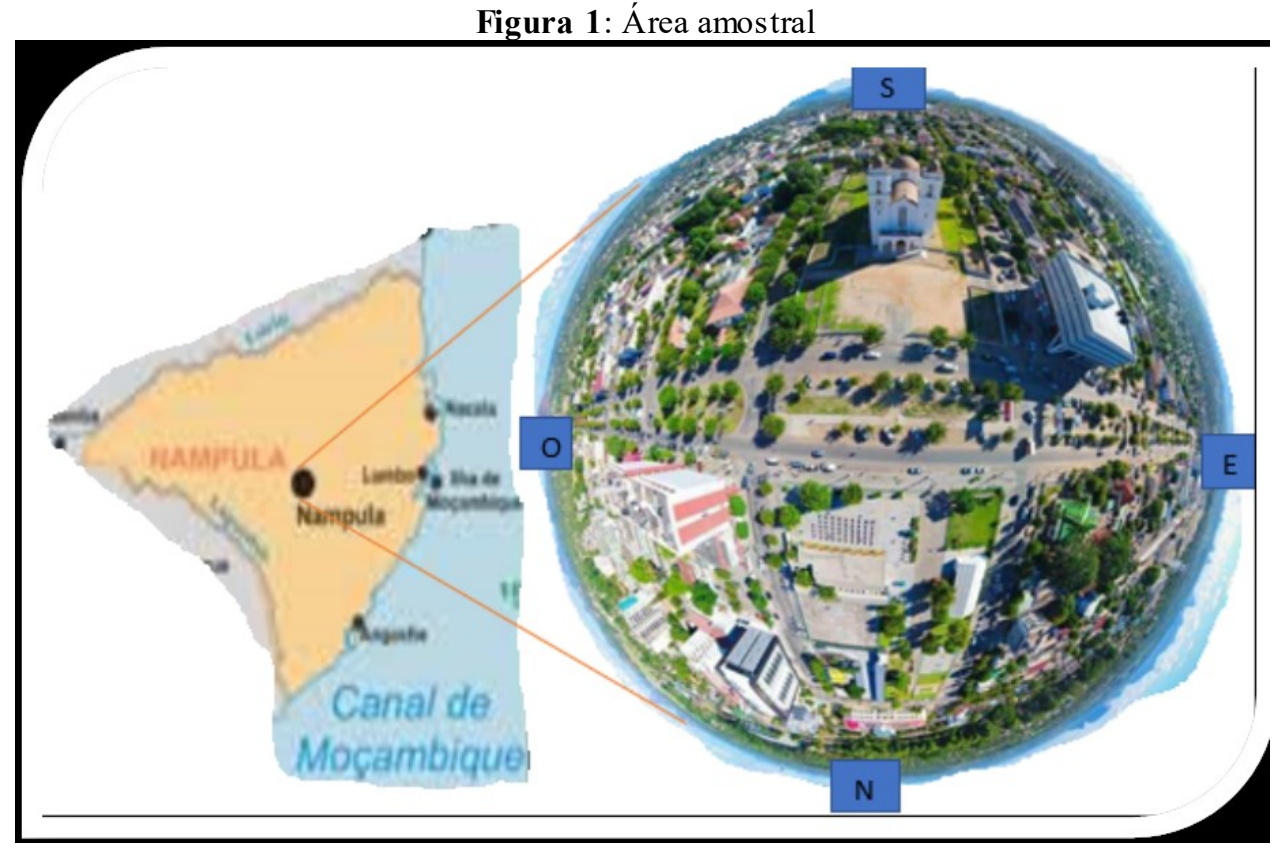

\footnotetext{
${ }^{4}$ Fonte: Instituto Nacional de Estatística - $\underline{\text { http://www.ine.gov.mz/ }}$
} 


\subsubsection{Enquadramento da Palavra "Ecologia" no Tema}

"A ecologia de organismos ou autoecologia estuda a acção do meio sobre os seres vivos e as reacções destes. A ideia essencial da ecologia é a de uma adaptação, isto é, de uma correlação entre os organismos e seu meio" (PRENANT, 1934 apud DAJOZ, 2008, p. 25), ou seja, há uma necessidade dos seres vivos adaptarem-se em função dos recursos oferecidos pelo ambiente.

Entende-se por carbonização o processo pelo qual a madeira ou lenha é submetido ao tratamento térmico a temperaturas elevadas, com objetivos de produzir um produto de alto teor de carbono chamado carvão vegetal. No entanto, este produto é resultante de um processo químico que consiste na reação (madeira/lenha + calor) para obter-se carvão vegetal, vapores e gases.

Em Moçambique o carvão vegetal é largamente utilizado para confeccionar alimentos. Contudo, para o presente estudo foi produzido um produto com base em materiais provenientes da madeira (resíduos de papel e aditivo) através de um processo físico, conservando os componentes como $\mathrm{C}, \mathrm{H}, \mathrm{N}, \mathrm{O}, \mathrm{S}^{5}$, cujo o processo de carbonização acontece durante a utilização do produto e não na produção como é o caso de carvão vegetal. Portanto, o fim pelo qual se destina o produto proposto é equivalente ao do carvão vegetal daí a atribuição do nome "Carvão Ecológico".

\subsubsection{Conceito de Filtração}

A filtração é uma operação pelo qual se separa o sólido dum líquido ou gás mediante um meio poroso, que retém os sólidos, mas deixa passar o fluido. O filtro mais apropriado para qualquer operação determinada é aquele que preencher os requisitos com o mínimo custo global. Visto que o custo de equipamento está inteiramente relacionado com a área de filtração (COULSON e RICHARDSON, 1965, p. 53).

Para Coulson e Richardson (1965, p. 75), “entende-se por filtro de placa uma superfície filtrante que pode ser encaixada numa armadura de suporte ou apoiados num par de trilho. A superficie pode ser sulcada ou lisa".

\footnotetext{
${ }^{5}$ Elementos químicos: $\mathrm{C}=$ carbono; $\mathrm{H}=$ hidrogênio; $\mathrm{N}=$ nitrogênio; $\mathrm{O}=$ oxigênio; $\mathrm{S}=$ enxofre.
} 


\subsubsection{Conceito de Secagem}

Coulson e Richardson (1965, p. 657), definem secagem como "a remoção final de água nos materiais, em alguns casos, a secagem é uma parte essencial de um processo, como por exemplo, a produção de carvão ecológico proposto neste trabalho, como uma das formas para acabamento de carvão". Ainda segundo esses autores, "na maioria das indústrias transformadoras, a secagem faz-se por uma ou várias das seguintes razões: para reduzir o custo de transporte, para tornar o material manejável, para dar determinadas propriedades, para evitar a presença de humidade que pode provocar corrosão" (COULSON e RICHARDSON, 1965, p. 657). Dessa forma,

[...] há alguns aspectos gerais principais que se podem apontar: um secador pode ser usado para funcionamento continuo ou descontinuo; o aquecimento pode ser por passagem directa de ar ou gases quente através ou por sobre a subsistência, ou o aquecimento pode ser indirecto; o secador pode funcionar apenas à pressão atmosférica ou pode funcionar também sob vácuo (COULSON e RICHARDSON, 1965, p. 661).

\subsubsection{Avaliação Econômica}

Entende-se por estudo de viabilidade a avaliação custo-beneficio e o público alvo de um certo projeto (DOLABELA, 1999). A viabilidade proporciona uma resposta ou desejo de investir ou não para abertura de um empreendimento. Segundo Dolabela (1999) a criação de um bom negócio dá-se primeiro pela identificação de uma oportunidade, e em seguida pelo estudo da viabilidade desse negócio. Nesse contexto, foram efetuadas visitas às comunidades (exemplo na comunidade de Namitio segundo mostra a fotografia 3, para perceber o processo de aquisição de combustível lenhoso). 


\section{Debates Insubmissos}

Revista

Fotografia 3 - Acompanhamento de processo de abate de árvores para produção de lenha

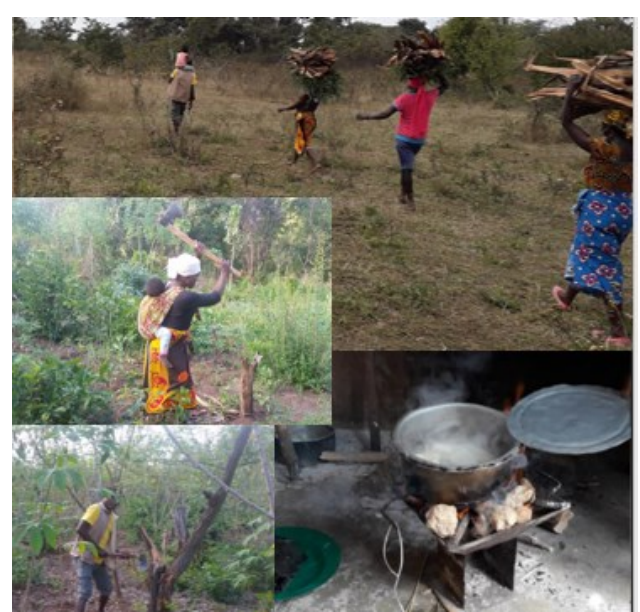

Fonte: Autor (2019)

Conforme Dolabela (1999), os custos podem ser divididos em fixos ou variáveis. Os fixos são gastos periódicos e necessários para manter o funcionamento de uma instituição e esses não são considerados para avaliação de custo unitário de produção visto que são custos relacionados, por exemplo, com salários, rendas ou aluguel. Já os custos variáveis são os que aumentam ou diminuem de acordo com a produção, ou seja, possuem relação direta com o nível de produção de um empreendimento.

Para Maximiano, (2006, p. 26), “entende-se por projeto como sendo um empreendimento temporário ou uma sequência de atividades com começo, meio e fim programados, que tem por objetivo fornecer um produto singular, dentro de restrições orçamentárias". Um empreendimento novo, sempre traz com ele as incertezas e riscos.

\section{METODOLOGIA}

Segundo (Ruiz 1996, p. 138), "o termo método significa o traçado das etapas fundamentais da pesquisa, enquanto o termo técnico significa os diversos procedimentos ou utilização de diversos recursos peculiares a cada objeto de pesquisa, dentro das diversas etapas do método". 


\title{
Debates Insubmissos
}

Revista

\begin{abstract}
"ciência", saber. Pode-se dizer que a Metodologia Científica consiste no estudo, geração e verificação dos métodos, técnicas e processos utilizados na investigação e resolução de problemas, para o desenvolvimento do conhecimento científico (RODRIGUES, 2014, p. 13).
\end{abstract}

\subsection{Tipo de Pesquisa Quanto aos Procedimentos Técnicos}

No que diz respeito aos procedimentos técnicos, optou-se pela pesquisa experimental, uma vês que se procurava o aprofundamento de uma realidade específica (otimização do processo de produção de carvão ecológico). Basicamente, realizou-se por meio de coleta de resíduo de papel e pó de madeira como matéria-prima. Posteriormente, avaliou-se o poder calorífico, fez-se a caracterização químico-física e a interação dos constituintes do produto.

Experimentalmente foram usados diferentes tipos de fogões para avaliar o rendimento calorífico do carvão ecológico em comparação com carvão tradicional ou vegetal produzido na base de lenha.

Método experimental consiste em submeter o fenômeno estudado à influência de certas variáveis, em condições controladas e conhecidas pelo pesquisador, para observar os resultados que as variáveis produzem no objecto. O delineamento consiste em definir um objeto para estudo, selecionar as variáveis que seriam capazes de influenciá-lo e determinar as formas de controle e de observação dos efeitos que a variável escolhida produz no objeto (RODRIGUES, 2014 p. 163).

Na ótica de Ventura (2002, p. 79) "a pesquisa de campo deve merecer grande atenção, pois devem ser indicadas os critérios de escolha de amostragem (das pessoas que serão escolhidas como exemplares de certa situação), a forma pela qual serão coletados os dados e os critérios de análise dos dados obtidos".

Dependendo da complexidade de um trabalho de pesquisa, é pertinente e fundamental chegar ao campo para ir viver de perto a situação que deseja pesquisar para melhor coletar os dados e apurar. Só com estas informações ou dados do campo é que torna possível validar as hipóteses e ter uma plena confiança do assunto em estudo. 


\title{
3.2. Instrumentos de Elaboração de Questionário
}

Para a presente pesquisa, como instrumentos de elaboração de questionário recorreu-se ao inquérito, onde aleatoriamente foram fornecidas amostras de carvão ecológico a algumas famílias na cidade de Nampula tendo sido contemplados 10 inqueridos.

\subsection{Amostra da Pesquisa}

A amostra numa pesquisa diz respeito a uma parte ínfima retirada do universo, com a qual se trabalha e serve de prova das conclusões que se tiram.

\begin{abstract}
A amostragem por conglomerados é indicada em situações em que é bastante difícil a identificação de seus elementos.É o caso, por exemplo, de pesquisas cuja a população seja constituída por todos os habitantes de uma cidade. Em casos desse tipo é possível proceder à seleção da amostra a partir de "conglomerados". Conglomerados típicos são quarteirões, famílias, organizações, edifícios, fazendas (GIL, 2008, p. 93).
\end{abstract}

Assim, no que tange à amostra, para esta pesquisa foram privilegiados os terminais de resíduos (lixeiras de Natikire, Namicopo e Sera da mesa), locais de maior aglomeração tal como foi no Mercado Grossista Aresta, Mercado Central, Escola Secundária de Nampula e Instituições Industriais, Corredor de Desenvolvimento do Norte - CDN e Corredor Logístico de Nacala - CLN.

\section{ETAPAS DE POTENCIAÇÃO DE CARVÃO ECOLÓGICO}

\subsection{Diagnóstico de Resíduos de Papel}

A situação ambiental de referência na área de estudo teve como objetivo descrever as condições ambientais que se verificam atualmente no meio físico e biótico. Para a realização de diagnostico ambiental foram efetuadas uma série de visitas e observações nos locais com potencial de geração dos resíduos tais como as lixeiras municipais, escolas, Universidades e empresas, para certificar a forma de acondicionamento temporário, tratamento e deposição final além da descrição dos impactos ou consequências.

Atualmente, existem três terminais de resíduos na cidade de Nampula, nomeadamente, lixeira Crispim, lixeira Natikire e lixeira Namicopo. A primeira difere das outras duas por tratar- 
se de um espaço plano enquanto que as outras duas são buracos, isto é, antigas áreas de exploração de solo (áreas de empréstimos) abandonados sem a devida recuperação. No entanto, todas elas têm algo em comum, cheiro nauseabundo, resíduo não segregados (mistura de resíduo orgânico, papel, plástico, vidros e resíduos industriais) segundo mostra a fotografia 4.

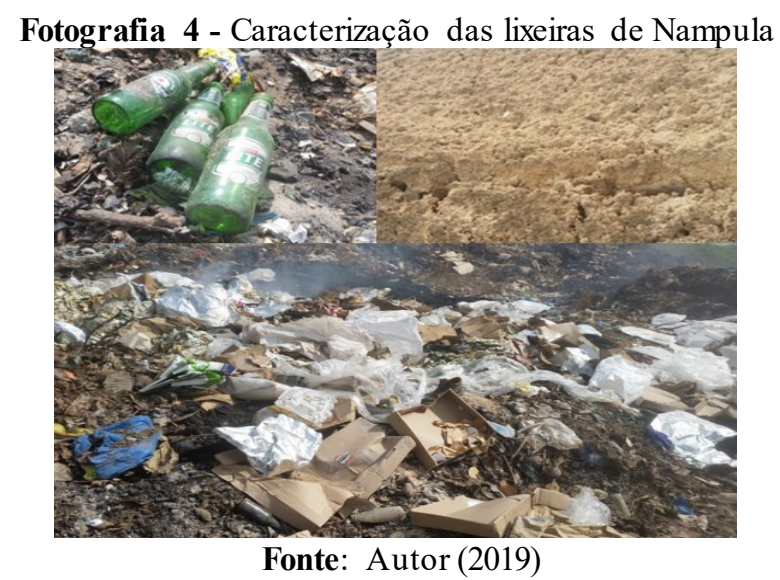

No entanto, os principais impactos relacionados com a disposição de papel na área de referência são:

- Obstrução de vias de acesso;

- Obstrução de canais de passagem de águas ou drenagens;

- Proliferação de baratas, ratos que são vectores causadores de doenças;

- Inutilização de espaços agrícolas e;

- Sensação de mal-estar pela aparição de sujeira de papel em locais públicos.

\subsubsection{Instrumentos Usados}

Para operacionalização do processo produtivo de carvão ecológico foram combinados diversos materiais e instrumentos tais como: redutor de tamanho de papel, recipientes plásticos, balança, máquina de calcular, misturador e filtros de placa. A fotografia 5 abaixo apresenta a vista geral destes materiais que foram usados em todo processo de produção de carvão ecológico. 


\section{Debates Insubmissos}

Revista

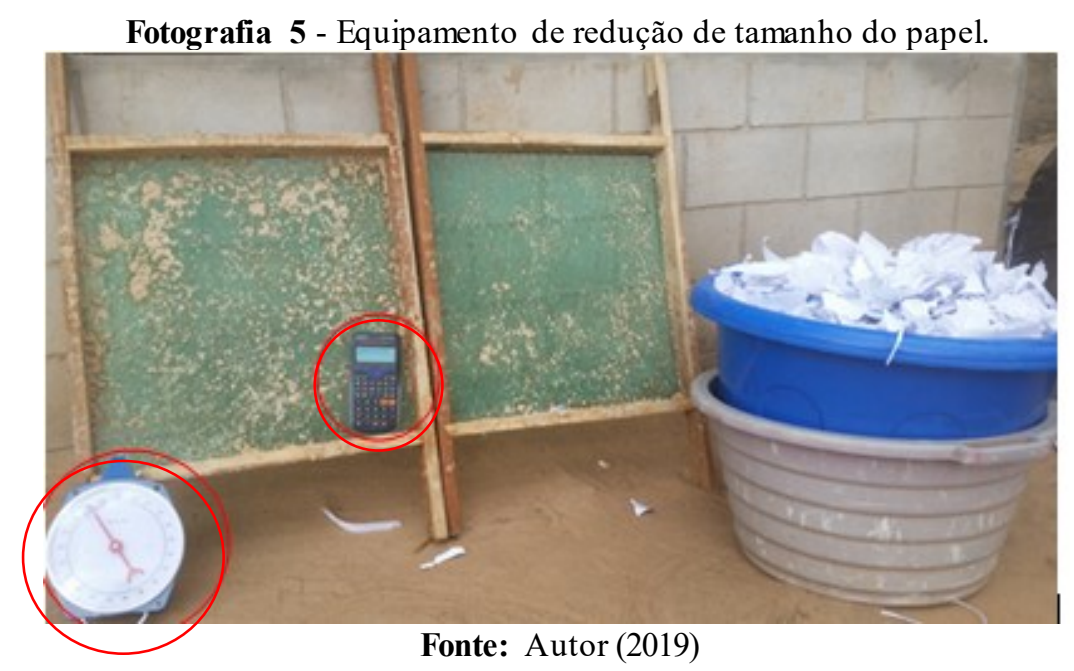

No entanto, o filtro de placa que nos é mostrado foi dimensionado e encomendado pelo autor do trabalho a um carpinteiro de acordo com a necessidade do trabalho, tendo sido utilizado para retirada excessiva de humidade na massa de papel.

\subsection{Etapa de Produção}

Para a potenciação do carvão ecológico produzido na base de papel foram usadas as seguintes etapas: i) Coleta de Resíduo; ii) Seleção e tratamento; iii) Pesagem; iv) Preparação da massa de papel; v) Filtração; vi) Granulometria; vii) Secagem; viii) Embalagem; e ix) Armazenamento.

\subsubsection{Coleta de Resíduos de Papel}

Consistiu na montagem de sistema de controlos ambientais ou eco pontos na Escola Secundária de Nampula e no escritório da empresa corredor logístico de Nacala para acondicionamento temporário de resíduos de papel, segundo mostra a fotografia 6 . 
Revista

Debates Insubmissos

Fotografia 6 - Montagem de sistemas de controlo ambiental na escola secundária de Nampula

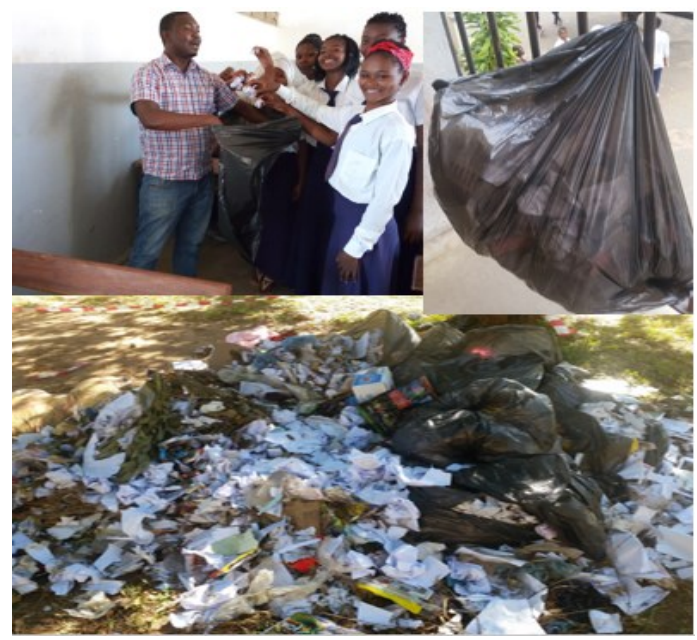

Fonte: Autor (2019)

O saco plástico mostrado na fotografia 6 é exemplo de muitos outros que estiveram pendurados nos pisos da escola secundária de Nampula para o depósito dos resíduos de papel produzidos durante as aulas que depois eram transportados para outro ponto para acondicionamento temporário e pesagem, cuja a média diária era de $131 \mathrm{~kg}$ de resíduos de papel durante 23 dias úteis.

Gráfico 1: Quantidade de resíduos de papel gerados na escola secundária no mês de maio em 2019

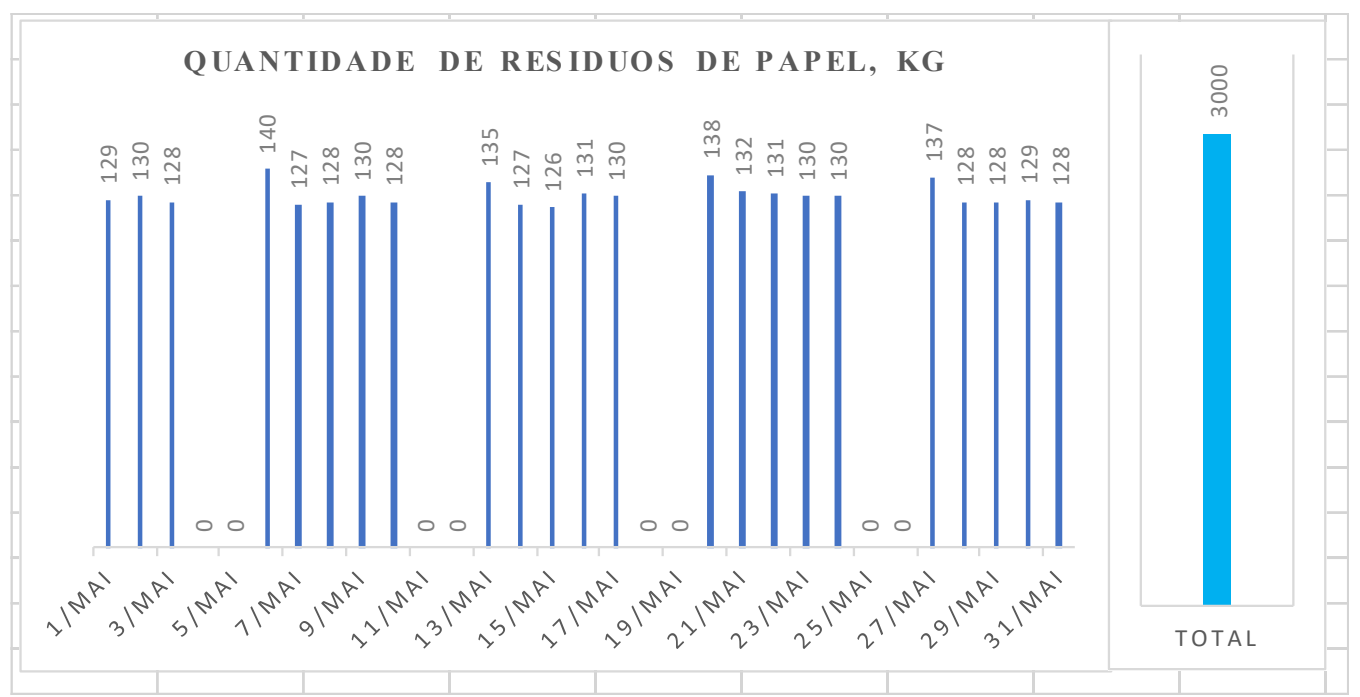

Fonte: Autor (2019) 
No entanto, com base no estudo, prevê-se em 2019 a geração de 27 toneladas de resíduos de papel na escola secundária de Nampula contra 26 escolas secundárias e 6 universidades existentes na cidade de Nampula.

\subsubsection{Seleção e Tratamento do Resíduo.}

Por causa de algumas falhas no ato de coleta e depósito, foi necessário remover do conjunto de resíduos de papel os outros resíduos não adequados ou objetos estanhos, tendo sido selecionado o papel de natureza mais leve, diferente do papelão para depois efetuar-se a redução de tamanho (corte em pedaços mais pequenos) por método manual ou instrumental, como mostra a fotografia 7 .

Fotografia 7 - Destruidor de papel da marca IDEAL 3104 fabrico Alemão

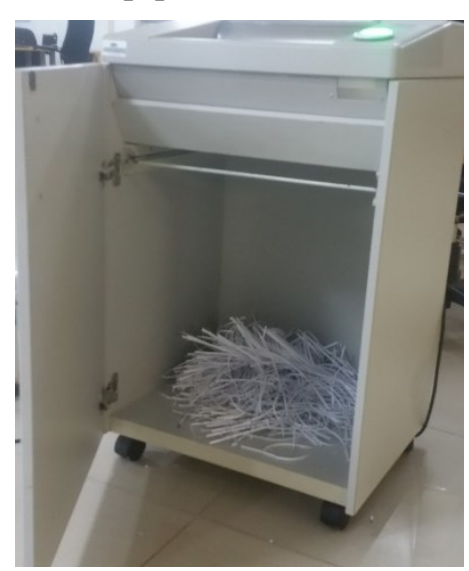

Fonte: Autor (2019)

Para utilização do pó de madeira (aditivo) foi necessário que o mesmo estivesse isento de partículas maiores passando pelo processo de teste visual para adequação do material através de retirada de objetos ou produtos estranhos.

\subsubsection{Pesagem}

A fotografia 8 mostra o momento de pesagem do papel antes de se colocar em molho (água) para a preparação da massa. 
Fotografia 8: Pesagem de resíduos de papel e pó de madeira

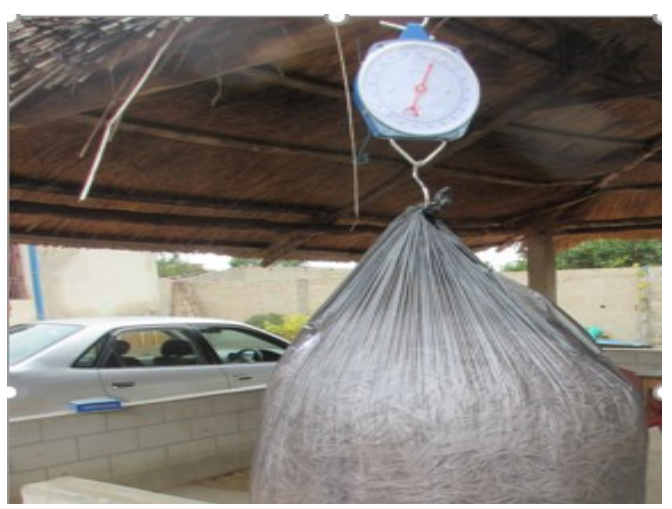

Fonte: Autor (2019)

\subsubsection{Preparação da Massa de Papel}

A preparação da massa consiste em colocação do papel previamente pesado, adição de água até uma quantidade que permita e facilite a massagem do papel, a massagem deve ser feita até que o papel se transforme em massa consistente (com tendência de massa pastosa). No entanto, após a verificação da tonalidade da massa segundo mostra a fotografia 9 , foi adicionado $30 \%$ de pó de madeira.

Fotografia 9: Preparação da massa de papel

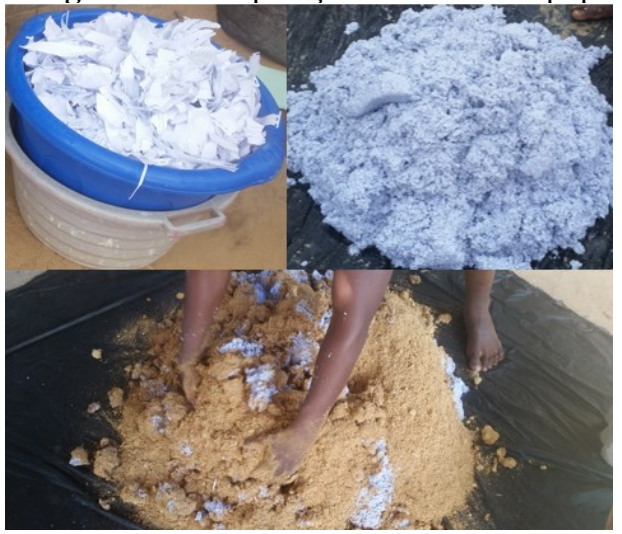

Fonte: Autor (2019)

A adição do pó de madeira deveu-se pelo facto da mesma otimizar ou melhorar a superficie de contato e rigidez dos graus de carvão, embora cientificamente não tenha sido provado esta capacidade que o pó de madeira demostrou quando em contato com a massa de papel. 


\subsubsection{Filtração}

Em alguns casos, após a massa ser preparada e estar pronta para a formação da granulometria (carvão), pode-se notar muita humidade dificultando a formação dos graus pelo processo manual sendo necessário filtrar. Neste caso, foram utilizados filtros de placa preparados para o efeito segundo mostra a fotografia 10, mas podem ser usados outros filtros como o de prensa.

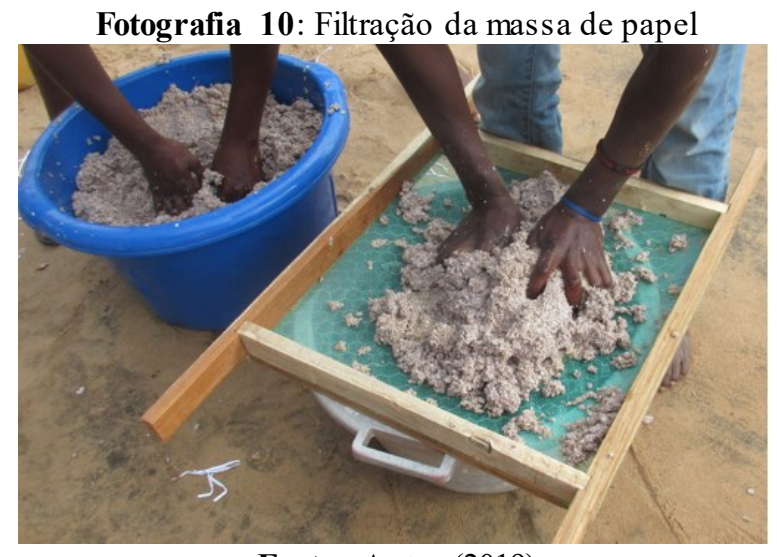

Fonte: Autor (2019)

\subsubsection{Granulometria}

A forma superficial e o tamanho das partículas do carvão foram determinados pela capacidade de acumulação da quantidade da massa de papel na mão e a força do prensamento aplicada, tendo-se considerado a necessidade de colocar o máximo de massa que coubesse na mão de modo a obter-se partículas de diâmetros médio não inferiores a $3.0 \mathrm{~cm}$.

\subsubsection{Secagem}

Foi usada secagem natural com base na luz do sol, tendo sido colocado o carvão através de uma superficie impermeabilizada que não permita o contato com o solo ou areia antes da secagem de modo a conservar o produto e evitar interferências com elementos não combustíveis no produto segundo mostra a figura 12 . 


\section{Revista Debates Insubmissos}

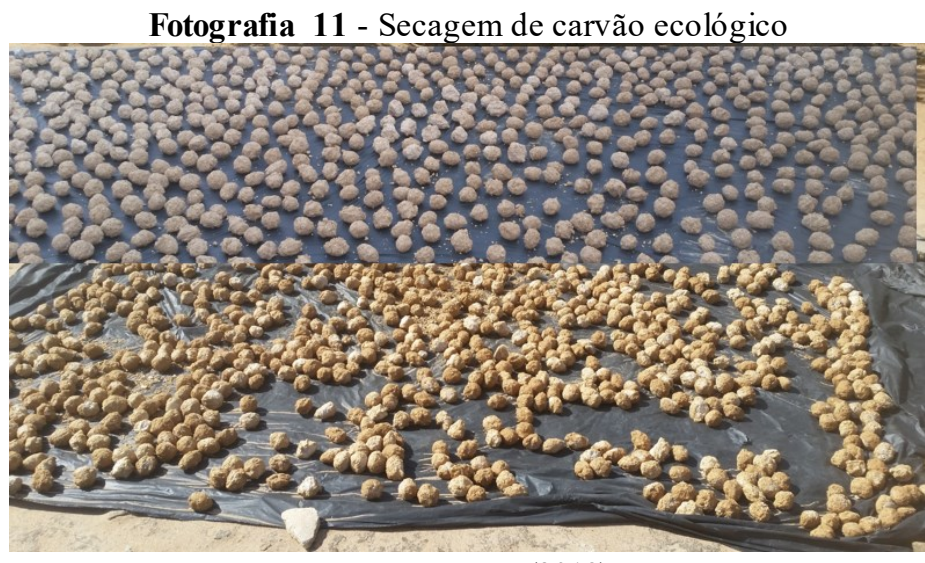

Fonte: Autor (2019)

\subsubsection{Embalagem e Armazenamento}

Sendo um material poroso e com possibilidade de desagregação das partículas que a compõem por causa da fraca compactação, deve ser embalado em sacos que o protejam de humidade ou molha e guardar em local seco.

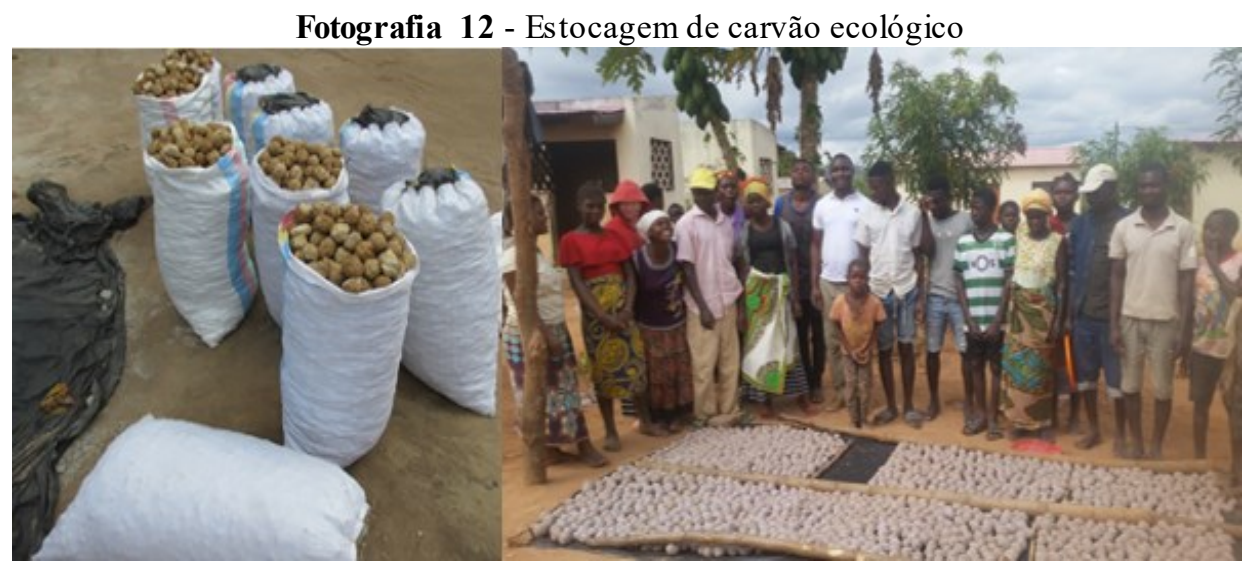

Fonte: Autor (2019)

\subsection{Avaliação do Tempo Útil de Emissão de Calor}

A avaliação do tempo útil de emissão de calor térmico consistiu na fervura de água em quatro panelas de mesma capacidade volumétrica e natureza, com mesma quantidade de água. A fervura foi realizada em quatro fogões de características diferentes usando 600 gramas de carvão ecológico em comparação com carvão tradicional ou vegetal, segundo mostra a fotografia 13 . 
Revista

Debates Insubmissos

Fotografia 13 - Testes experimentais do tempo de emissão de calor térmico

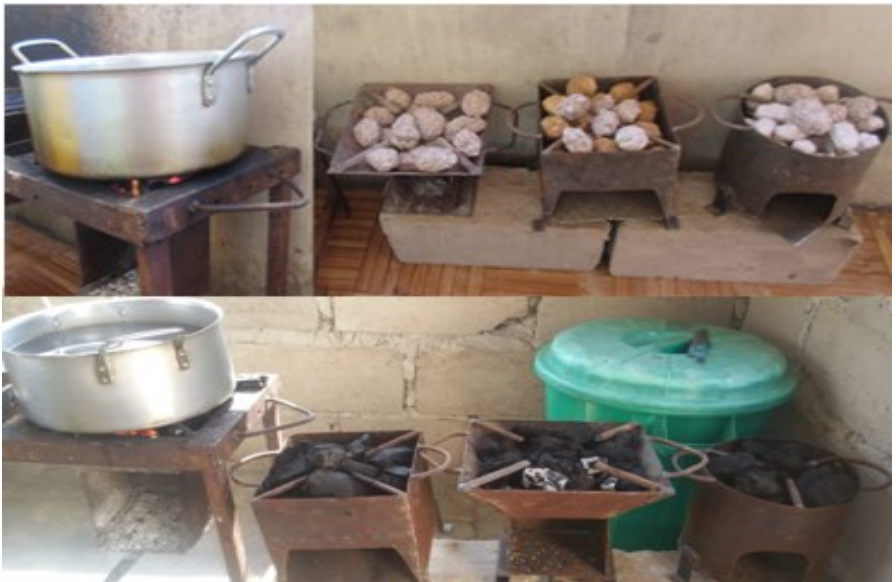

Fonte: Autor (2019)

O termo "tempo útil" refere-se ao tempo de emissão de calor térmico gasto desde o inicio de fervura até o término.

Tabela 4: Resultados de ensaios de optimização da composição

\begin{tabular}{|c|c|c|c|}
\hline $\begin{array}{l}\text { Composição de } \\
\text { Carvão (\%) }\end{array}$ & $\begin{array}{c}\text { Quantidade de } \\
\text { Carvão (g) }\end{array}$ & $\begin{array}{l}\text { Tempo de } \\
\text { Fervura (min.) }\end{array}$ & $\begin{array}{c}\text { Quantidade de } \\
\text { Cinza (g) }\end{array}$ \\
\hline \multirow{5}{*}{100} & \multirow{5}{*}{600} & 9 & 11.5 \\
\hline & & 10 & 11.6 \\
\hline & & 8 & 10.5 \\
\hline & & 10 & 11.0 \\
\hline & & 8 & 10.4 \\
\hline \multirow{5}{*}{$90 / 10$} & \multirow{5}{*}{600} & 12 & 15.2 \\
\hline & & 11 & 15.3 \\
\hline & & 13 & 14.7 \\
\hline & & 12 & 15.0 \\
\hline & & 12 & 14.8 \\
\hline
\end{tabular}




\begin{tabular}{|c|c|c|c|}
\hline \multirow{5}{*}{$85 / 15$} & \multirow{5}{*}{600} & 14 & 23.0 \\
\hline & & 15 & 22.8 \\
\hline & & 13 & 23.2 \\
\hline & & 14 & 22.9 \\
\hline & & 14 & 23.1 \\
\hline \multirow{5}{*}{$80 / 20$} & \multirow{5}{*}{600} & 18 & 42.0 \\
\hline & & 17 & 42.2 \\
\hline & & 19 & 41.8 \\
\hline & & 18 & 42.3 \\
\hline & & 18 & 41.7 \\
\hline \multirow{5}{*}{$75 / 25$} & \multirow{5}{*}{600} & 22 & 60.0 \\
\hline & & 21 & 60.4 \\
\hline & & 21 & 60.2 \\
\hline & & 23 & 59.4 \\
\hline & & 23 & 60.0 \\
\hline \multirow{5}{*}{$70 / 30$} & \multirow{5}{*}{600} & 30 & 80.0 \\
\hline & & 31 & 80.3 \\
\hline & & 31 & 80.4 \\
\hline & & 30 & 79.3 \\
\hline & & 28 & 80.0 \\
\hline
\end{tabular}

Fonte: Elaborado pelo autor (2019)

Os ensaios mostrados na tabela 4 acima permitiram a fixação da composição do carvão ecológico proposto com $70 \%$ papel e $30 \%$ pó de madeira. 
O processo resumo de como e qual foi o método usado para a escolha do material residual de papel pode ser visualizado no fluxograma 1 .

Fluxograma 1: tipo de material e método a ser usado

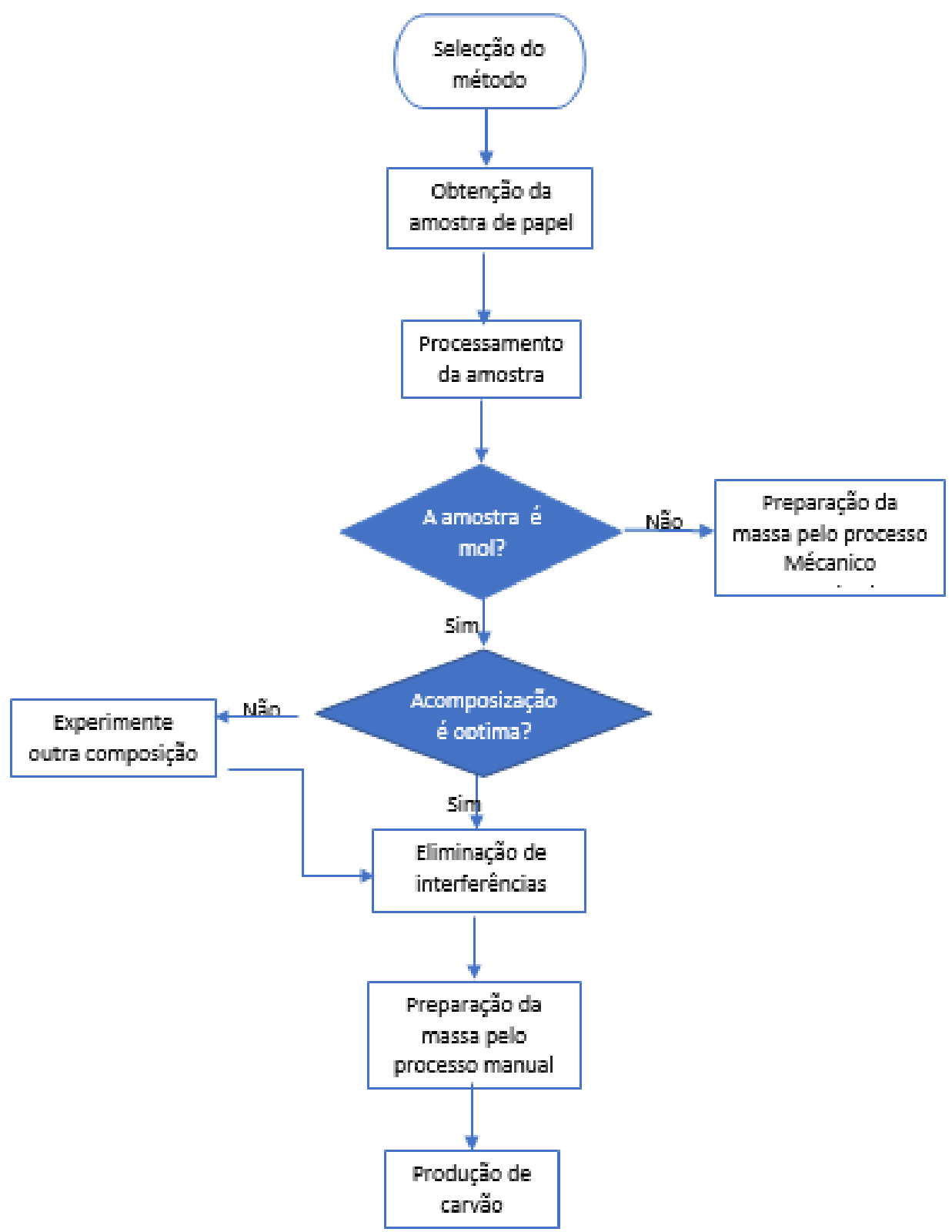

Fonte: Elaborado pelo autor (2019)

O fluxograma mostra as etapas envolvidas em uma análise experimental. Existem caminhos possíveis para percorrer as etapas em uma análise experimental. No exemplo mais 
simples, representado pela sequência vertical central, selecionou-se um método, adquiriu-se e processou-se a amostra, amoleceu-se a amostra em solvente apropriado (água), preparou-se a massa de papel pelo processo manual e produziu-se o carvão. Dependendo da complexidade da amostra e do método escolhido, várias outras etapas podem ser necessárias.

\section{TRATAMENTO DE DADOS}

Após a otimização da composição (mistura) ideal para o produto proposto foram realizados os testes de produção do produto modelado para avaliar o valor médio do tempo útil de emissão de calor térmico e quantidade de cinza gerada, segundo mostram os resultados na tabela 5 .

Tabela 5: Resultados do tempo útil de emissão de calor térmico

\begin{tabular}{|c|c|c|c|}
\hline Iten & $\begin{array}{c}\text { Quantidade de } \\
\text { Carvão (g) de } \\
\text { Composição (70/30) }\end{array}$ & $\begin{array}{l}\text { Tempo útil de } \\
\text { Fervura(min.) }\end{array}$ & $\begin{array}{c}\text { Quantidade de } \\
\operatorname{Cinza(g)}\end{array}$ \\
\hline \multirow{5}{*}{ Fugão 1} & \multirow{5}{*}{600} & 26.0 & 80.0 \\
\hline & & 25.0 & 80.2 \\
\hline & & 27.0 & 80.5 \\
\hline & & 27.0 & 79.3 \\
\hline & & 26.0 & 80.0 \\
\hline \multirow{5}{*}{ Fugão 2} & \multirow{5}{*}{600} & 30 & 86.0 \\
\hline & & 31 & 86.5 \\
\hline & & 29 & 86.2 \\
\hline & & 29 & 86.0 \\
\hline & & 31 & 85.3 \\
\hline \multirow{5}{*}{ Fugão 3} & \multirow{5}{*}{600} & 27 & 81.0 \\
\hline & & 28 & 81.4 \\
\hline & & 28 & 81.5 \\
\hline & & 26 & 80.5 \\
\hline & & 26 & 80.6 \\
\hline
\end{tabular}




\begin{tabular}{|c|c|c|c|}
\hline \multirow{3}{*}{ Fugão 4 } & \multirow{3}{*}{600} & 29 & 84.0 \\
\cline { 3 - 4 } & & 29 & 84.4 \\
\cline { 3 - 4 } & & 28 & 84.5 \\
\cline { 3 - 4 } & & 28 & 83.5 \\
\cline { 3 - 4 } & & 30 & 83.6 \\
\hline
\end{tabular}

Fonte: Elaborado pelo autor (2019)

\subsection{Viabilidade Econômica}

Foram levantados todos os custos relacionados com aquisição de material, equipamentos, transporte, perdas no processo de produção para estimar-se o custo unitário de produção de carvão doméstico e estimativa do custo da pesquisa, segundo mostra a tabela 6 .

Tabela 6: Levantamento de despesas

\begin{tabular}{|l|c|}
\hline \multicolumn{1}{|c|}{ Item } & $\begin{array}{c}\text { Custos de Inves tigação } \\
\text { (Mt) }\end{array}$ \\
\hline Resíduo de Papel & 0 \\
\hline Pó de madeira & 0 \\
\hline Balanças & 1000 \\
\hline Sacos Vazios de 60kg & 200 \\
\hline Sacos Plásticos & 2000 \\
\hline Água & 150 \\
\hline Máquina de Calcular & 750 \\
\hline Filtros & 700 \\
\hline Lona plástica & 500 \\
\hline Bacias, Balde, Galão & 250 \\
\hline Outros & 2000 \\
\hline & 7550 \\
\hline
\end{tabular}

Fonte: Elaborado pelo autor (2019)

\subsection{Resultados do Inquérito de Satisfação e Percepção}

O avanço da ciência desde os tempos remotos teve como objetivo melhorar a vida da sociedade ou comunidades, neste contexto como forma de avaliar a recepção do produto 
proposto para o mercado local foi feito um inquérito de acordo com o questionário da tabela 7 . Participaram no inquérito 10 pessoas, entre membros da comunidade, estudantes e professores.

Tabela 7: Resultados do inquerito de satisfação e perceção

\begin{tabular}{|l|c|c|}
\hline \multicolumn{3}{|c|}{ INQUÉRITO DE PERCEPÇÃO E SATISFAÇÃO } \\
\hline \multicolumn{1}{|c|}{ QUES TÕES } & Número de Pess oas \\
\cline { 2 - 4 } & Sim & Não \\
\hline 1. O carvão acende bem? & 10 & -- \\
\hline $\begin{array}{l}\text { 2. O tempo de queima é satis fatório e dá para } \\
\text { cozer alimentos? }\end{array}$ & 8 & -- \\
\hline $\begin{array}{l}\text { 3. O que achou da ideia de produzir carvão } \\
\text { ecológico através de resíduos de papel. Você } \\
\text { aconselharia as pessoas a abraçarem a ideia? }\end{array}$ & 10 & -- \\
\hline $\begin{array}{l}\text { 4. Se um saco de carvão ecológico for produzido } \\
\text { com todos os detalhes e custa-se 60 meticais você } \\
\text { compraria? }\end{array}$ & 8 & -- \\
\hline
\end{tabular}

Fonte: Elaborado pelo autor (2019)

\subsection{Demonstração dos Cálculos}

\subsubsection{Média de tempo útil de emissão de calor térmico}

$$
X_{T f}^{-}=\frac{\sum X_{i}}{n}=\frac{26+25+27+26+26}{5}=26 \mathrm{~min} .
$$

4.3.2. Média da Quantidade de Cinza gerada

$$
\bar{X}_{Q c z}=\frac{\sum X_{i}}{n}=\frac{80.0+80.2+80.5+79.3+80.0}{5}=80 \mathrm{gr}
$$

\subsubsection{Custo Total de Produção}


Para avaliação de custo de produção e custo unitários foram considerados custos fixos da matéria prima, tais como:

- Custo de Resíduo de papel =0,0 mt;

- Custo do aditivo (Pó de madeira) =0,0mt;

- Custo de água=150,0mt;

- Custo de transporte=200;0 mt

- Quantidade de resíduo de papel usado=182,5kg

- Quantidade do aditivo (Pó de madeira) $=26,7 \mathrm{~kg}$

- Quantidade de stokes (sacos) produzidos=10;0

- Custo total de Produção (Ctp)=350;0 mt

$$
\mathbf{C} \mathbf{p}=\frac{C_{t p}}{Q_{p}}=\frac{350 \mathrm{mt}}{10 \mathrm{st}}=35 \mathrm{mt} / \mathrm{st}
$$

\section{APRESENTAÇÃO DOS RESULTADOS}

Resultados do processo de otimização das composições dos resíduos de papel e o aditivo (pó de madeira) são mostrados na tabela 8 .

Tabela 8: Resultados para diferentes composições

\begin{tabular}{|c|c|c|c|}
\hline Composição & $\begin{array}{c}\text { Quantidade } \\
\text { de Carvão (g) }\end{array}$ & $\begin{array}{c}\text { Tempo de } \\
\text { Fervura (min.) }\end{array}$ & $\begin{array}{c}\text { Quantidade } \\
\text { de cinza (g) }\end{array}$ \\
\hline 100 & 600 & 9 & 11 \\
\hline $90 / 100$ & 600 & 12 & 15 \\
\hline $85 / 15$ & 600 & 14 & 23 \\
\hline $80 / 20$ & 600 & 18 & 42 \\
\hline $75 / 25$ & 600 & 22 & 60 \\
\hline $70 / 30$ & 600 & 30 & 80 \\
\hline
\end{tabular}

Fonte: Elaborado pelo autor (2019) 
Gráfico 2: Avalição de tempo úteis de emissão de calor térmico v composição.

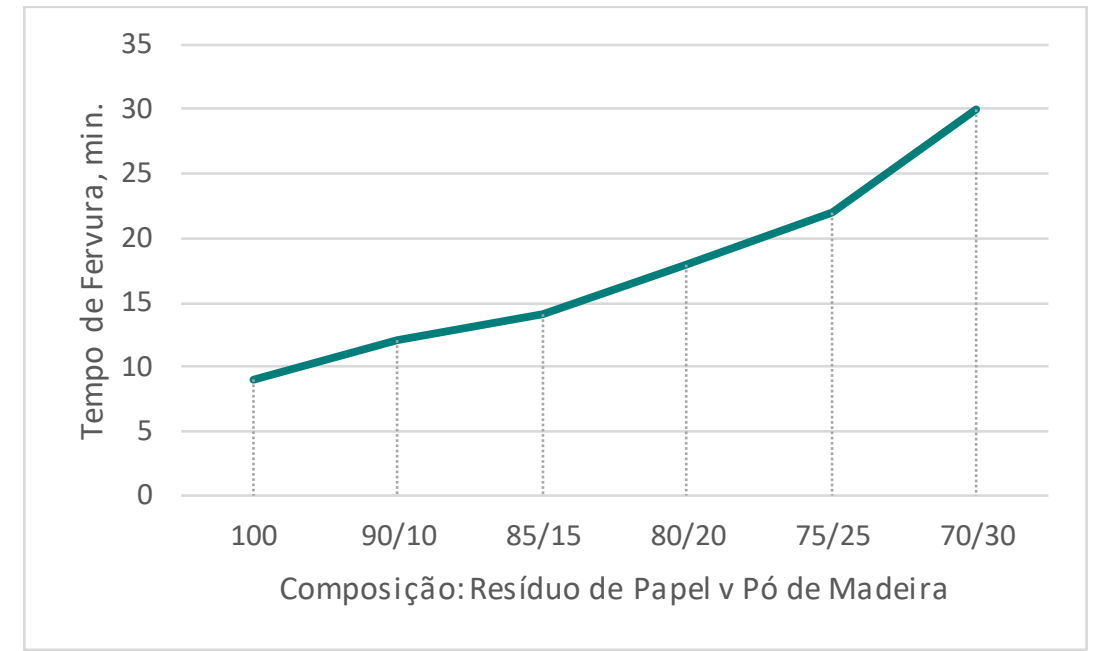

Fonte: Elaborado pelo autor (2019)

Gráfico 3: Avalição da quantidade de cinza gerada v composição

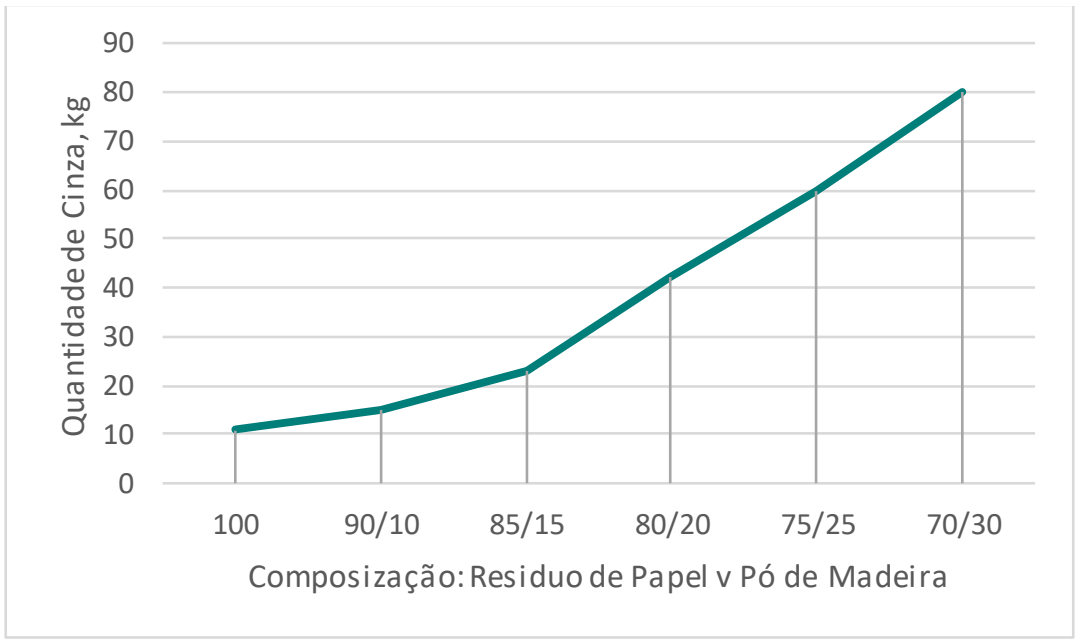

Fonte: Elaborado pelo autor (2019)

Os resultados das médias dos tempos úteis de emissão de calor térmico e as respectivas cinzas geradas do carvão proposto (modelado) são a presentadas a seguir na tabela $9 \mathrm{em}$ comparação com o carvão vegetal. 
Revista

Debates Insubmissos

Tabela 9: Resultados de tempos útis de emissão de calor térmico e cinza gerada

\begin{tabular}{|c|c|c|c|c|c|}
\hline \multirow{2}{*}{ Item } & \multirow{2}{*}{$\begin{array}{l}\text { Quantidade de } \\
\text { Carvão (g) }\end{array}$} & \multicolumn{2}{|c|}{ CARVÃO ECOLÓGICO } & \multicolumn{2}{|c|}{ CARVÃO VEGETAL } \\
\hline & & $\begin{array}{c}\text { Tempo de } \\
\text { Fervura (min.) }\end{array}$ & $\begin{array}{l}\text { Quantidade de } \\
\text { Cinza (g) }\end{array}$ & $\begin{array}{c}\text { Tempo de } \\
\text { Fervura (min.) }\end{array}$ & $\begin{array}{l}\text { Quantidade de } \\
\text { Cinza (g) }\end{array}$ \\
\hline Fugão 1 & 600 & 26 & 80 & 43 & 69 \\
\hline Fugão 2 & 600 & 30 & 86 & 41 & 73 \\
\hline Fugão 3 & 600 & 27 & 81 & 42 & 75 \\
\hline Fugão 4 & 600 & 29 & 84 & 42 & 75 \\
\hline$\sum$ & 2400 & 112 & 331 & 168 & 288 \\
\hline$X$ & & 28 & 82,75 & 42 & 72 \\
\hline
\end{tabular}

Fonte: Elaborado pelo autor (2019)

Gráfico 4: tempo útil de emissão de calor térmico versus fugão.

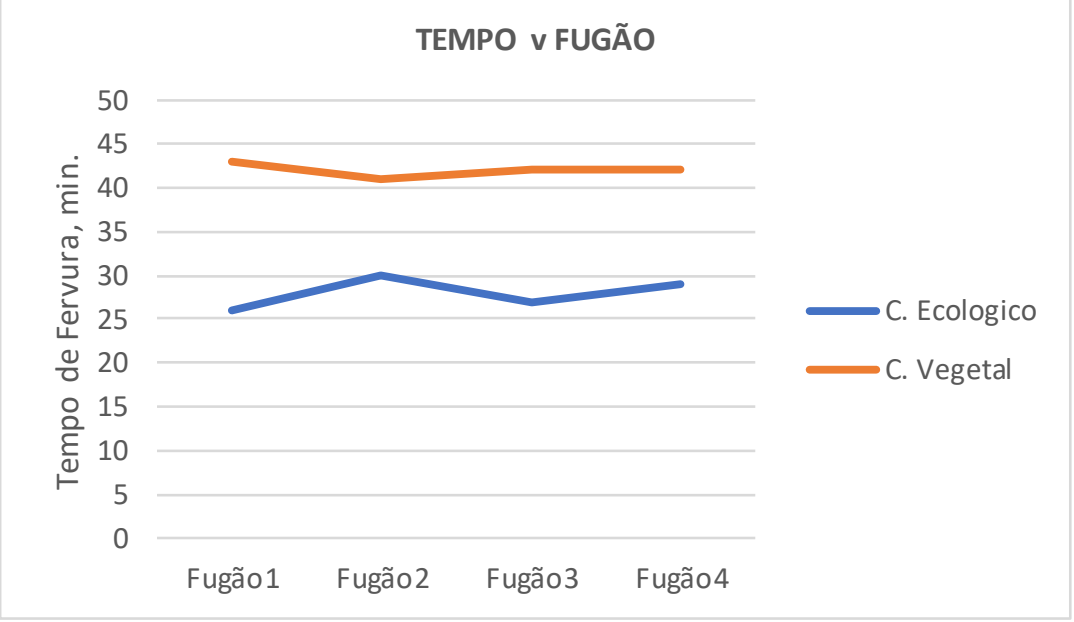

Fonte: Elaborado pelo autor (2019) 
Gráfico 5: quantidade de cinza gerada versus Fugão.

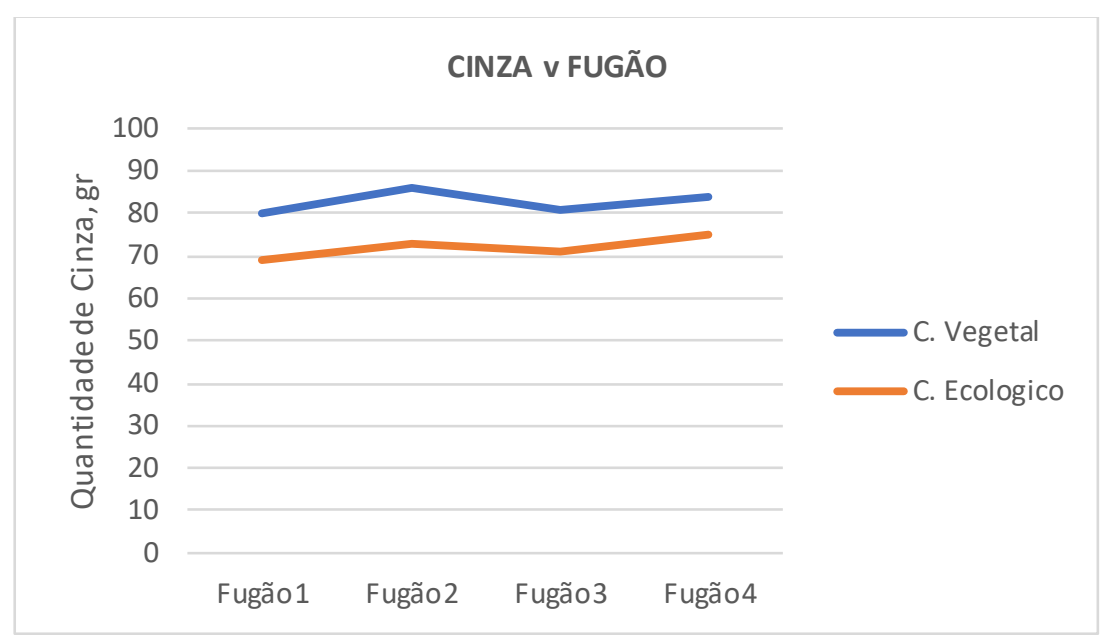

Fonte: Elaborado pelo autor (2019)

\subsection{Análise Comparativa}

Após vários testes realizados os resultados mostram algumas vantagens entre o carvão ecológico e carvão vegetal, tal como facilidade de acender e maior temperatura de chama, sendo mais alargadas as vantagens quando comparado com lenha segundo o resumo da tabela 10.

Tabela 10: Resumo das vantagens

\begin{tabular}{|l|l|}
\hline \multicolumn{1}{|c|}{ CARVÃO ECOLÓGICO } & \multicolumn{1}{c|}{ CARVÃO VEGETAL } \\
\hline Fácil de iniciar o lume & Difícil de iniciar o lume \\
\hline Armazenagem Racional & Grandes áreas para armazenamento \\
\hline $\begin{array}{l}\text { Redução da Mão de Obra no } \\
\text { Manuseio }\end{array}$ & Maior Mão de Obra \\
\hline Maior Temperatura da Chama & Menor Temperatura da Chama \\
\hline Isento de Licenças Especiais & Licenças Especiais \\
\hline Maior Teor de Cinzas & Baixo Teor de Cinzas \\
\hline
\end{tabular}

Fonte: Elaborado pelo autor (2019) 


\subsection{Discussão dos Resultados}

O produto proposto (carvão ecológico) teve aceitação em todas acamadas da sociedade de acordo com o inquérito de satisfação, uma vês que mais de metade dos inqueridos responderam positivamente as questões colocadas. No entanto, os dois pontos com $100 \%$ de resposta positiva estão relacionados com a facilidade de queima e rapidez na emissão de calor térmico. No que concerne à produção de resíduos de cinza, os valores são bem próximos entre o carvão ecológico e o vegetal $82,75 \mathrm{gr} / 600 \mathrm{gr}$ e $72 \mathrm{gr} / 600 \mathrm{gr}$, respectivamente, contra um tempo útil de emissão de calor térmico de 28 minutos e 42 minutos, respectivamente, segundo mostram os resultados de ensaios. Algumas pessoas das comunidades questionaram sobre como adquirir os resíduos de papel, porém, o papel é facilmente visualizado como resíduo em Nampula em locais públicos, escolas, além do que é gerado pelas organizações visitadas como CLN, CDN, COCA COLA e CDM, onde é selecionado e embalado, mas não encontra utilidade ou destinação adequada. A partir da estimativa feita, a Escola Secundária de Nampula prevê a geração de 27 toneladas para o ano de 2019 contra 26 escolas secundárias e 6 universidades existentes na cidade de Nampula além das quantidades geradas pelas maiores companhias da cidade anteriormente referidas e, outras instituições não contabilizados no diagnóstico de resíduos. O custo de produção de um saco de $60 \mathrm{~kg}$ (stock) foi de $35 \mathrm{mt}$.

\section{RECOMENDAÇÕES}

A continuidade do estudo para verificação de mais detalhes que podem ter ficado a margem neste trabalho e verificação de oportunidades de reaproveitamento de outros resíduos;

Melhoraria do tempo útil de emissão de calor térmico e redução da porosidade do carvão através do aumento da força de compactação pelo processo de mecanização do sistema de produção;

Melhoraria do processo de quantificação de RSU através de instalação de balanças industriais para pesagem dos resíduos na gestão municipal; 
Melhoraria do processo de acondicionamento temporário em postos intermediários através de implementação de medidas de coleta seletiva para a valorização dos resíduos e redução de custos de descarte;

Implementação e divulgação do processo de produção de carvão ecológico nas instituições, comunidades ou aos munícipes no geral; e

Sistematização do plano de educação ambiental para conscientizar a população em matéria de meio ambiente.

\section{REFERÊNCIAS}

ARAÚJO, Manuel Mendes. Cidade de Nampula: a rainha do norte de Moçambique. Finnisterra: Revista Portuguesa de Geografia, Lisboa, v. 40, n. 79, p. 209-222, 2005.

COULSON, John.; RICHARDSON, Jack. Tecnologia Química Volume-II. London, 1965.

DAJOZ, Roger. Princípios de ecologia. ed. 7, Lisboa: Artmed, 2008.

DOLABELA, Fernando. O segredo de Luísa. São Paulo: Cultura Editores Associados, 1999.

GIL, Antonio Carlos. Métodos e Técnicas de Pesquis a Social 6a edição. São Paulo: Atlas, 2008.

GRIPPI, Sidney. Reciclagem e sua His tória: guia para as prefeituras municipais. Rio de janeiro. 2001.

MAXIMIANO, Antonio César Amaru. Administração de Projetos: como transformar ideias em resultados. São Paulo: Atlas, 2006.

MICOA. Estrátegia de Gestão Integrada de Resíduos Sólidos Urbanos em Moçambique . Maputo, 2012.

MOÇAMBIQUE. Lei número 20/1997 de 1 de outubro. Lei de Ambiente. Maputo: Edição Boletim, 1997.

RODRIGUES, Auro de Jesus. Metodologia científica. Aracaju: UNIT, 2014224 p. il.: $22 \mathrm{~cm}$ RUIZ, João Álvaro. Metodologia científica: guia para eficiência nos estudos. São Paulo: Atlas, 1996;

VENTURA, Deisy. Monografia jurídica. Porto Alegre: Livraria do Advogado, 2002. 


\section{Anexo 1}

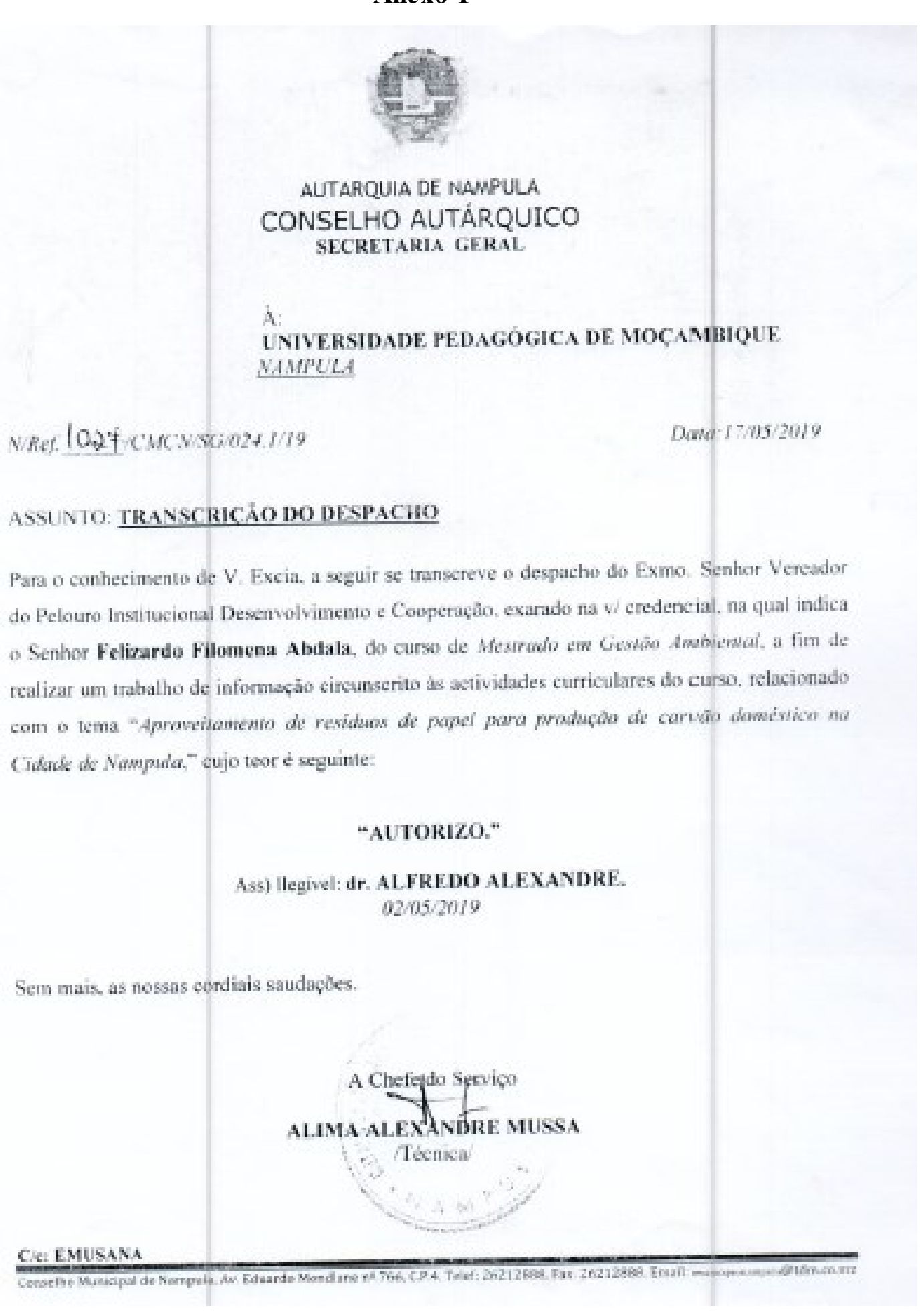




\section{Anexo 2}

\section{IFLORESTAS}

Tabela l: Licenciamento Florestal, Produção Industrial, Exportação e Reflorestamento

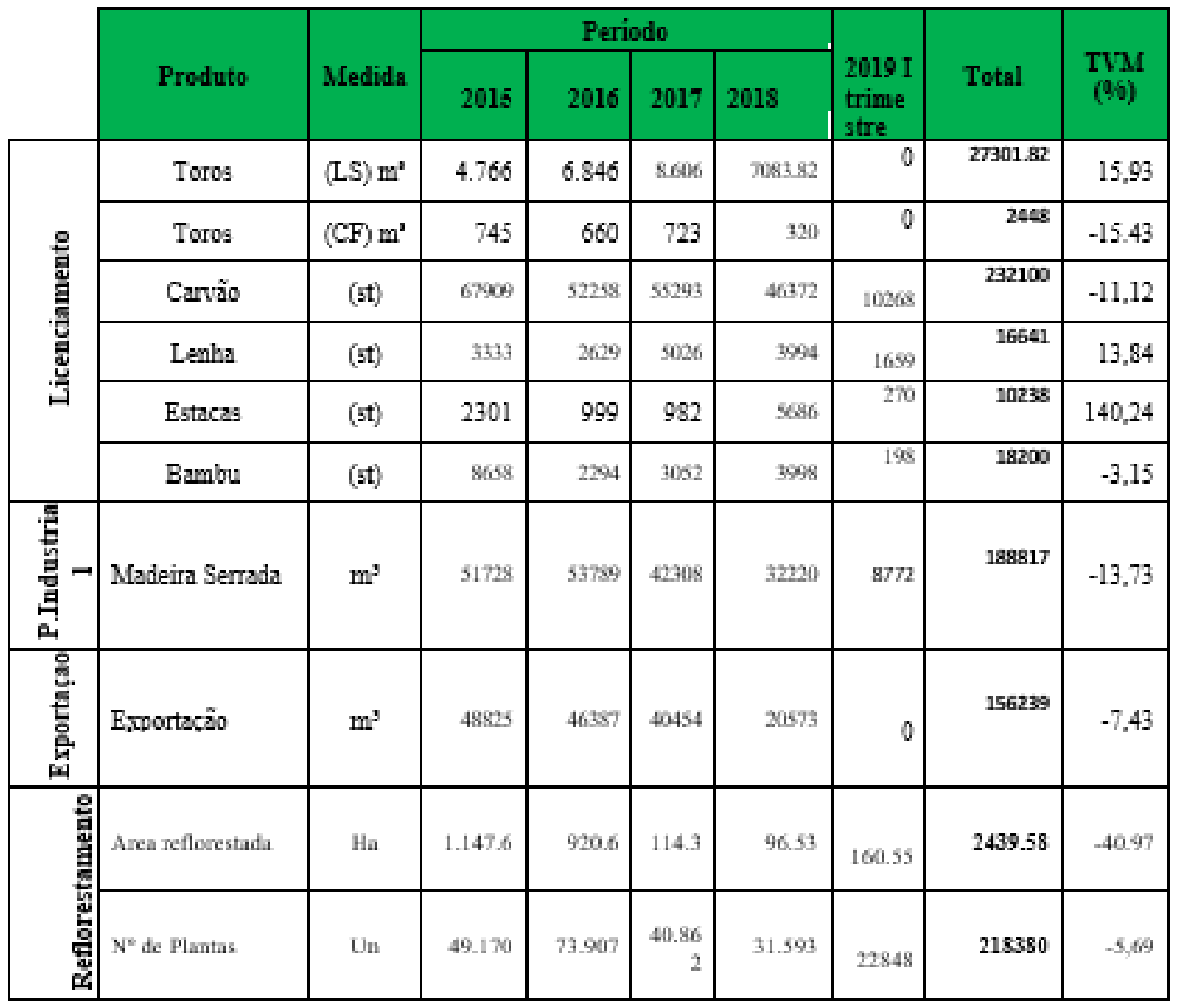

LS- LICENCA SIMPLES

CF- CONCESSAO FLORESTAL

ST-ESTERES 


\section{Anexo 3}

\section{$12 \mathrm{~B}_{3 / 4}$}

1. Niside Enmestimon-

$2-T o k s$ Non bor

3- Coftwo seabatinuma.

4- Nelsan Patricio -

5. Zaimabo Herminio Buamen-

6. Julieter Tamas

7 - Zuhaida pedeo

8- Jackisan parlo

9- Xandreque Victarino

10- Farto Jaus panlo - 846746956

11. Bactira Mieo Sidáno - B $3 / 5-842443253$

12 - Inés carlos NEVES B3/5-

13. Istela Molsés Inoforio B3/5-8uln3toga

14 - Marlieo pamioo Chele B3/5

15- Durce saide $B_{B} / 3$

16-Edson Artur $B_{3}$ ls

17 - Loide flfredo Bols

18. Liane lowito $\mathrm{B} B \mathrm{l}_{3}$

19-Germido fritur Bols. 
Revista
Debates Insubmissos

Anexo 4

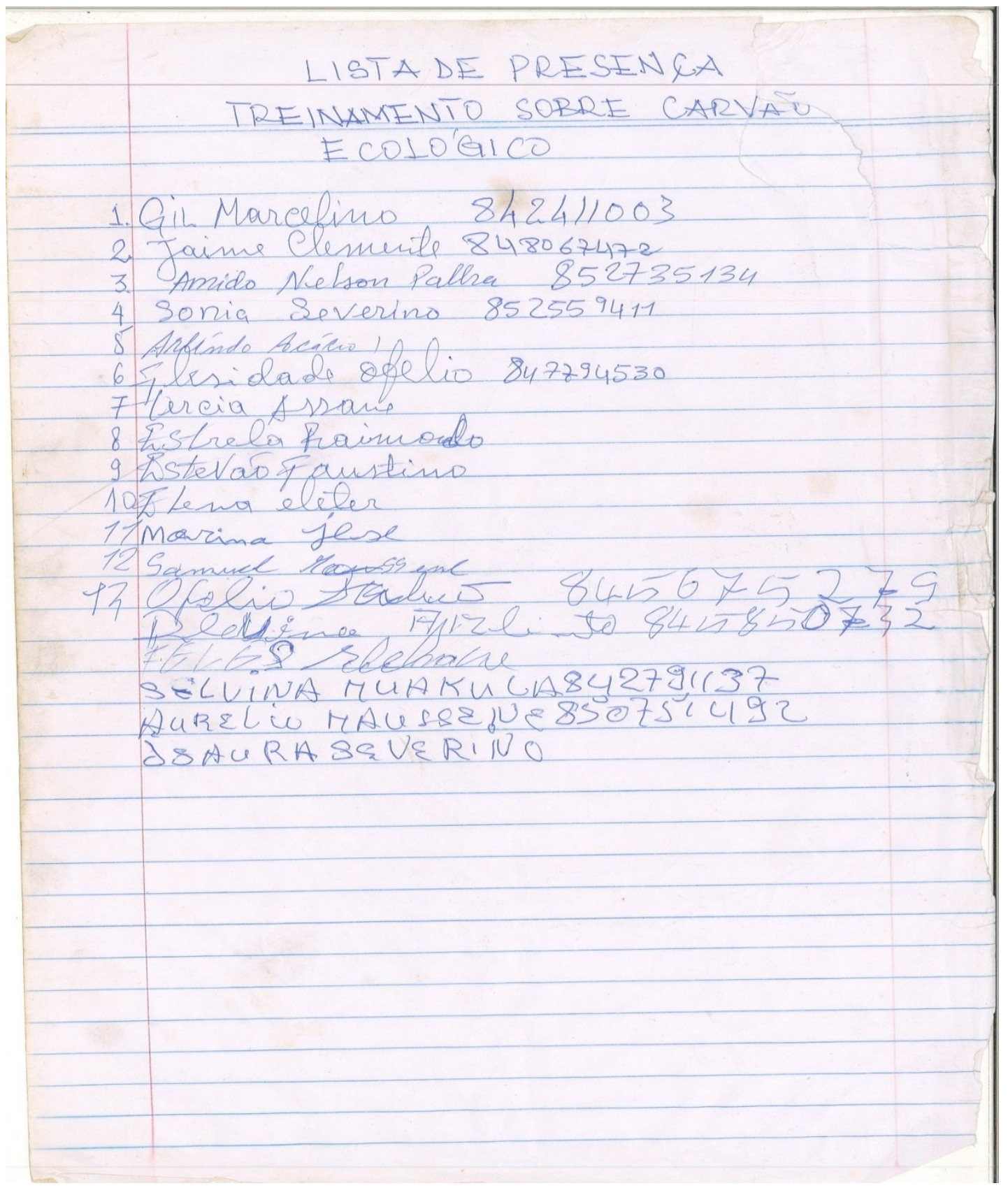

Submetido em: 10/10/2019

Aprovado em: 19/11/2019

REVISTA DEBATES INSUBMISSOS, Caruaru, PE. Brasil, Ano 2, v.2, no 7, set./dez. 2019. ISSN: 2595-2803

Endereço: https://periodicos.ufpe.br/revistas/debatesinsubmissos/ 